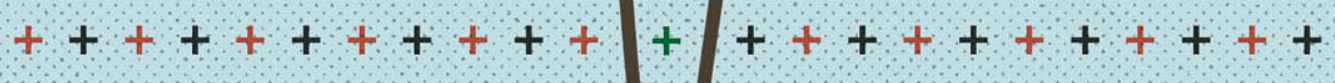
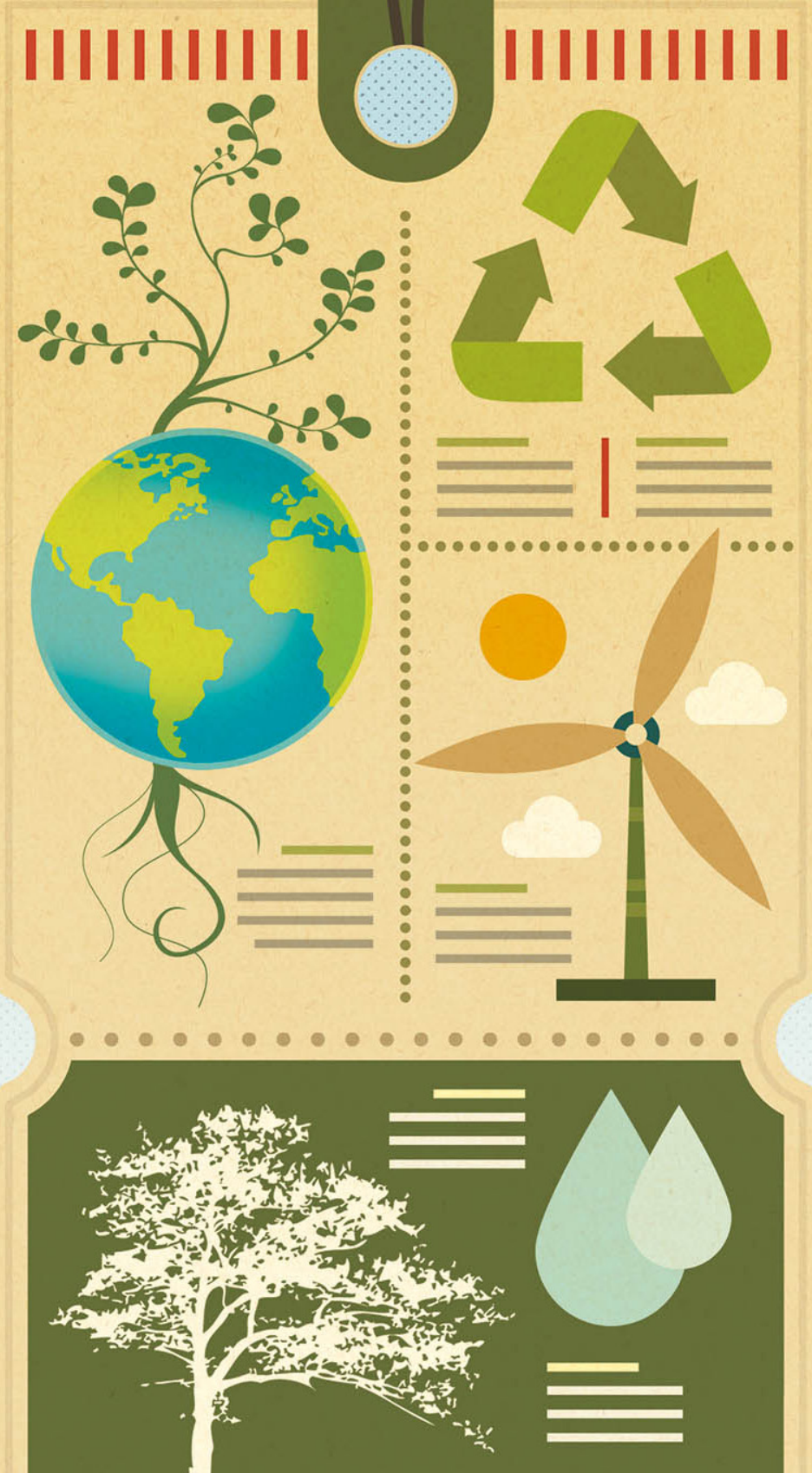


\section{A disposição a pagar pela sustentabilidade ambiental}

\section{The willingness to pary for environmental sustoinability}

* Joona d'Arc Bicalho Félix

\section{** André Nunes}

\section{Resumo}

O artigo investiga a disposição do consumidor em pagar por produtos ecologicamente sustentáveis. Os resultados da pesquisa apontam que os consumidores estão dispostos a substituir o produto habitualmente consumido por outro que seja correto do ponto de vista da sustentabilidade. A condição para a substituição é a obtenção de informações esclarecedoras e confiáveis sobre os reais atributos de sustentabilidade do produto ou marca.

Palavras-chave: Disposição a Pagar; Consumo Sustentável; Eco eficiência.

\begin{abstract}
The article delves into consumers' willingness to pay for environmentally sustainable products. The survey results indicate that consumers are willing to replace the product usually consumed for one that is correct from the sustainability point of view. The condition for replacement is the obtainment of enlightening and reliable information about the actual sustainability attributes of the product or brand.
\end{abstract}

Keywords: Disposition to Pay; Sustainable Consumption; Eco-efficiency.

\footnotetext{
* Doutora em Economia de Empresas pela UCB, Mestre em Planejamento e Gestão Ambiental, com linhas de pesquisa em Marketing Ambiental e Sustentabilidade Empresarial e professora do UniCEUB.

** Doutor em Economia pela Universidade de Brasília e professor da UNB E-mail: andrenunes@unb.br
} 


\section{Introdução}

$\mathrm{O}$ grande desafio para o desenvolvimento sustentável é inserir o consumidor nesse processo. Há muito tempo a preservação e a sustentabilidade tem sido uma atribuição inerente de governos e empresas. Sempre se buscou envolver o Governo, as empresas privadas e a sociedade civil no alcance de soluções para o forte impacto que o atual modelo de produção e consumo causa sobre a capacidade da terra de regenerar-se. Neste contexto, ganha espaço o termo Economia Verde, que exige um olhar sobre a capacidade de renovação natural da matéria-prima para que não seja inviabilizado o fornecimento futuro de insumos para a produção. Então, questionamse governos e empresas sobre o emprego de processos poluidores, que trazem ao meio ambiente subprodutos de forte impacto à saúde do Planeta Terra. É evidente que cabe às empresas papel fundamental para a sustentabilidade. Entretanto, não é dada a devida importância à participação do consumidor para o sucesso do processo. Em outras palavras, se ele não compra produtos que agridem a natureza, as empresas não os produzem.

O foco nas empresas é o mais comum. Elas têm sido cobradas quanto à eficiência energética em suas linhas de produção. São estimuladas a medir a economia de material, avanços tecnológicos, designs mais eficazes, maior aproveitamento da matériaprima, mudança cultural e controle de processos. Para Hawken e Lovins (1999) estamos a caminho de um novo modo de viver onde o ecossistema representa um ativo de excepcional valor. A Revista Conjuntura Econômica (2009) da FGV, afirma que as empresas brasileiras se destacam, na América Latina, em termos de sustentabilidade, responsabilidade social e governança. A revista se baseia em pesquisa da Management \& Excellence de 2009. A pesquisa avaliou a performance das 50 maiores empresas latino-americanas mostrando que as corporações brasileiras lideram o ranking em 140 critérios nas três categorias. A pesquisa cruza indicadores financeiros, análises de riscos e processos.

Para Porter (1990), Sachs (1993) e Kotler \& Roberto (1992) a sustentabilidade social e ambiental vem agregando valor às marcas e às empresas, de forma a contribuir com a sustentabilidade econômica, a médio e longo prazos. Conceitualmente, atuar de forma socioambientalmente correta significa: atuar de maneira ética e transparente; estabelecer uma relação ganha x ganha com a sociedade; praticar uma política de preços justos; gerenciar os impactos sociais e ambientais no ramo de negócios; ir além do respeito às leis trabalhistas e de direitos humanos; praticar a anticorrupção e o diálogo com stakeholders - que são todos os agentes que impactam ou são impactados pela atuação da empresa - antecedendo as tomadas de decisões estratégicas empresariais.

Infelizmente os esforços, até agora realizados, por empresas e governo não tem sido suficientes para minorar as pressões sobre o meio ambiente. Citando, novamente, o relatório Pegada Ecológica, que analisa o impacto que as ações humanas causam 
no meio ambiente, ele aponta que, em 2008, a humanidade usava recursos correspondentes a "um terço a mais da capacidade da Terra do que a efetivamente disponível, afetando a regeneração dos próprios ecossistemas dos quais a humanidade depende".

A mesma tendência foi mostrada em outubro de 2010 pela WWF - World Wildlife Fund ou Fundo Mundial para a Natureza. O relatório Planeta Vivo apontou que a humanidade consome $50 \%$ a mais do que a capacidade de renovação do Planeta, no que diz respeito ao ar limpo, qualidade do solo, água potável, e outros recursos naturais. Os dois relatórios apontam no mesmo sentido: o esgotamento dos recursos naturais no médio e longo prazos, motivado pela retirada descontrolada de insumos da natureza, não considera a capacidade de reposição, além do descarte de restos indesejados que pressionam, ainda mais, a saúde do sistema ambiental.

Capra (2002) lembra que as informações sobre as questões ambientais passaram a ser melhor compreendidas após os adventos da globalização da economia. Os consumidores, agora conectados em rede no mundo inteiro, podem perceber a ligação entre causas e efeitos em relação às alterações nos ecossistemas. Kotler (2000) e Kotler; Kartajaya \& Setianwan (2010) analisam o ambiente natural contemporâneo e acreditam que há uma importante preocupação global com a deterioração do meio-ambiente. Para o autor, problemas como: poluição do ar e da água, com índices perigosos em muitas cidades do mundo; o efeito estufa, que leva ao superaquecimento do Planeta; a pressão de grupos ambientalistas sobre a poluição industrial; as mudanças legislativas e legais levarão as empresas a investir bilhões em equipamentos de controle de poluição e em combustíveis menos nocivos ao meio ambiente.

Como a sociedade irá equacionar esta importante preocupação global? Estão as empresas dispostas a investir bilhões em equipamentos de controle de poluição por conta própria, reduzindo esses novos custos de seus lucros? É bastante provável que elas tentarão repassar os novos custos ao preço de seus produtos. Será que os consumidores estão dispostos a arcar com um novo patamar de custos que incorpore essa preocupação global? Em outras palavras, preocupação global é um termo bastante abrangente que envolve ações de governo, de empresas, de consumidores, de organizações não governamentais, além de uma efetiva mudança de hábitos da sociedade como um todo. O trabalho pretende investigar uma parte do problema: os consumidores estão dispostos a pagar mais caro por produtos ambientalmente corretos? Estrutura-se a partir do resumo dos fatores que podem influenciar nas preferências dos consumidores; seguido da metodologia empregada na pesquisa, dos principais resultados encontrados no estudo de campo e, finalmente, das considerações finais.

\section{O consumo sustentável}

É inegável o movimento de empresas, governo e consumidores no que tange a ampliação da consciência acerca da finitude dos recursos naturais, discurso cons- 
tantemente presente na mídia contemporânea. Entretanto, parece estar ainda inerte a mudança de comportamentos, apesar de dados alarmantes, principalmente em relação ao aquecimento global além dos limites considerados suportáveis à vida no Planeta. Todo este movimento em prol do conhecimento dos impactos é importante, mas parecem insuficientes para produzir uma mudança comportamental. A empresa irá produzir o que o consumidor desejar comprar.

Economistas acreditam que consumidores realizam compras para maximizar sua utilidade. Consumidores querem então saciar seus desejos e vontades que podem ser necessidades básicas ou até mesmo fruto de um hedonismo desenfreado. Na verdade, o que se busca é que o consumidor "sinta-se melhor" após o ato de consumir. Com esta consideração, tudo indica que um bom encaminhamento para a questão ambiental é fazer com que o consumidor fique "feliz" ao consumir produtos ecologicamente corretos. Parece, então, que parte importante do problema é como fazer para alterar a disposição a pagar e a disponibilidade a receber dos consumidores, de modo a inserir em suas funções de utilidade o desejo de consumir marcas e produtos ambientalmente responsáveis.

O caminho parece ser a produção de estímulos a valores agregados que devem ser "construídos" na mente do consumidor. Sabe-se que o consumidor paga por marcas e seus valores agregados e não obrigatoriamente por produtos de necessidade básica. Por este motivo, a psicologia comportamental dedicou-se a compreender a influência estímulo-resposta nas decisões e escolhas dos indivíduos. Perceber como se forma este processo mental pode vir a favorecer a criação de novos valores agregados em benefício da gestão empresarial que leva em conta o Tripé da sustentabilidade. A ideia de tripé é que além dos ganhos econômicos empresariais, sejam levados em conta na decisão, a análise dos impactos e das possibilidades sociais e ambientais em cada negócio, em cada processo. Para Elkington (2000), o gerenciamento dos aspectos sociais, ambientais e econômicos forma o conceito de Tripé da Sustentabilidade. Ele é a base para a compreensão do que viria a ser desenvolvimento sustentável, que orienta a necessidade de mudanças no antigo modelo de gestão empresarial, levando em conta um processo que busca ser o mais sustentável possível nas três dimensões.

O cenário real contemporâneo mostra que o capital impulsiona empresas, na mesma medida em que o consumo impulsiona pessoas. A Economia de mercado demonstra que a demanda orienta a oferta e o equilíbrio entre produção e consumo é realizado pelo próprio mercado. Então, empresas estarão interessadas em incluir aspectos sociais e ambientais às decisões econômicas, na mesma medida em que os consumidores considerarem que essas ações elevam o valor agregado do produto, ao ponto de darem preferência de compras a estas marcas. Algumas pesquisas levantam a hipótese de que está surgindo um 'novo consumidor' que estaria insatisfeito com o tradicional formato de produção x consumo insaciável. A pesquisa Percepção do Consumidor Brasileiro, elaborada pela Market Analysis (2007) mostra as principais expectativas dos consumidores em relação às práticas socioambientais das empresas: 
83\% dos entrevistados esperam que as empresas "tratem a todos os funcionários de forma justa", e 74\% "prefere produtos que não prejudicam o meio ambiente", sendo estas as práticas socioambientais das empresas mais esperadas por eles. Quando provocados, estes mesmos entrevistados respondem "estar muito interessados em saber como as empresas tentam ser socialmente responsáveis".

A Management and Excellence (2010) sugere ser, a sustentabilidade, um diferencial nos mercados maduros, ou seja, naqueles em que não mais há crescimento ou inovação. A diferenciação se processaria via investimentos em capacitação, esforços na retenção de profissionais e programas direcionados a ecoeficiência. A pesquisa sugere também que este diferencial implicaria em maior número de vendas e rentabilidade às empresas, pois os consumidores estariam dispostos a pagar pelos atributos socioambientais atrelados a marca. Vale aqui relembrar Oliveira (2004) reforçando que:

\footnotetext{
"O conhecimento efetivo sobre o ambiente é fundamental para o processo estratégico, o sentido de se obter a adequada compatibilidade entre a empresa e as forças externas que afetam seus propósitos, objetivos, desafios, metas, estratégias, políticas, estrutura, recursos, planos, programas, projetos, procedimentos e outros" [OLIVEIRA, 2004, p.93].
}

Desta forma, as informações externas (do ambiente externo) junto às informações internas (microambiente) irão orientar as decisões na gestão da marca.

Bernstein (1997) mostra que os indivíduos respondem a novos estímulos possuindo, como pano de fundo, um conjunto de preferências por eles consideradas importantes. Há, assim, um apego emocional vinculado a esta preferência. A decisão entre mais de uma escolha é um processo interativo no qual diversos fatores têm influência. Motivos intrínsecos como emoções, estado da mente, tendências e atitudes psicológicas em relacionar fenômenos podem influenciar nas decisões. Não se está dizendo com isso que o apego emocional faz o consumidor agir de modo irracional. Ele é mais um fator a ser considerado em sua escala de preferências.

A pesquisa desenvolvida nesse trabalho pretende demostrar, empiricamente, essa hipótese, ou seja, os estímulos para novos produtos, com atributos de sustentabilidade, trazem suficiente apelo emocional para que o consumidor substitua o produto atualmente consumido. Espera-se que os resultados da presente pesquisa contribuam para melhorar o entendimento desta questão.

\section{Metodologia}

A pesquisa de campo foi realizada com a busca de documentação direta, ou seja, a coleta de dados foi realizada no local. Avaliou-se, por meio de um experimento, se os consumidores, após sensibilização, estariam dispostos a mudar seus hábitos de consumo, trocando o produto que consomem por produtos com argumentos 
sociais e ambientais. A técnica permite perceber a existência de variações entre comportamentos a partir de estímulos realizados junto ao grupo experimental.

O produto sabão em pó foi escolhido para a pesquisa, por ser de uso comum a diversos públicos, estando presente nas casas de todas as classes sociais. O produto pertence à uma marca que se posiciona no mercado como livre de fosfato na fórmula e, por isto, reduz a agressão ao meio ambiente. Neste artigo, o denominaremos de Marca livre de fosfato. A amostra foi composta com pessoas entre 24 e 40 anos, pertencentes às classes sociais $A$ e $B$. Os consumidores receberam uma amostra do produto e respondem a um questionário.

O questionário compara o consumo do produto teste com outras marcas de sabão em pó e com o sabão mais consumido no país, que aqui denominaremos de Marca Top, visto ser a marca mais lembrada (Top of mind) no segmento de sabão em pó. O objetivo é perceber se o consumidor apresenta desejo de substituir, após o experimento, o produto habitualmente consumido pelo Marca livre de fosfato, devido a seus atributos de sustentabilidade.

Os convidados receberam amostras da Marca livre de fosfato, com a instrução de testar o produto, em suas residências, e responder a um questionário que foi entregue juntamente com a amostra. Os sujeitos de pesquisa foram escolhidos por conveniência e de modo aleatório. Foram convidados em corredores, na praça de alimentação, em salas de aula dos cursos de graduação e pós-graduação do Centro Universitário de Brasília (UniCEUB), Instituição de Ensino Superior localizada em Brasília, Distrito Federal. O recrutamento dos participantes, em todas as etapas, foi feito mediante abordagem convidativa e com amostra não probabilística do tipo acidental. Não foi oferecida nenhuma forma de recompensa pela participação na pesquisa. Os participantes tinham a oportunidade de abandonar a pesquisa a qualquer momento, fato que ocorreu, sobretudo, na pesquisa com o experimento. Nessa pesquisa foram entregues 100 questionários e amostras e, apenas, 41 foram devolvidos completamente preenchidos.

Aqueles que concordaram em participar da pesquisa foram informados sobre os argumentos ecoeficientes da marca, bem como da importância de haver produtos menos agressivos ao meio ambiente, como forma de contribuir com a preservação da natureza e das gerações futuras. A identidade dos pesquisados foi preservada. Os sujeitos de pesquisa deveriam devolver os questionários respondidos no prazo de uma semana.

Na elaboração dos questionários foi utilizada a escala Likert ${ }^{1}$ para construção das perguntas. A utilização dessa escala permite que as respostas resultantes possam ser avaliadas por uma medição psicométrica, comumente utilizada em pesquisas de opinião. O questionário foi, primeiramente, testado junto a 5 voluntários, antes de sua utilização definitiva, como forma de confirmação da clareza e compreensão das questões. 


\section{Resultados empíricos}

Esta seção é destinada a apresentação dos resultados da pesquisa. A Tabela 1, que identifica o hábito de consumo, resulta da primeira pergunta do questionário: "usou ultimamente, antes deste teste, as seguintes marcas e sabão em pó". Nela observase que os consumidores utilizam 12 marcas distintas de sabão em pó. Optou-se por preservar a identidade das marcas.

Tabela 1 - Hábito de Consumo de Sabão em Pó

\begin{tabular}{|l|c|c|}
\hline Marca de Sabão em Pó & $\begin{array}{c}\text { Número de } \\
\text { Consumidores }\end{array}$ & $\begin{array}{c}\text { Percentual da } \\
\text { Amostra (\%) }\end{array}$ \\
\hline Marca Top & 30 & 42,25 \\
\hline Marca C & 10 & 14,08 \\
\hline Marca D & 09 & 12,68 \\
\hline Marca E & 05 & 7,04 \\
\hline Marca F & 04 & 5,63 \\
\hline Marca livre de fosfato 1 & 03 & 4,23 \\
\hline Marca livre de fosfato 2 & 03 & 4,23 \\
\hline Marca G & 02 & 2,82 \\
\hline Marca H & 02 & 2,82 \\
\hline Marca I & 01 & 1,41 \\
\hline Marca J & 01 & 1,41 \\
\hline Marca K & 01 & 1,41 \\
\hline Total & 71 & 100,00 \\
\hline
\end{tabular}

Fonte: Pesquisa experimento

Os entrevistados podiam escolher mais de uma marca de sabão em pó. A Marca Top foi a mais escolhida. Então, antes da sensibilização, a Marca livre de fosfato, com seus dois produtos, teve $8,46 \%$ da amostra. A Marca Top teve $42,25 \%$ de consumidores. Ambas possuem preços similares. Estão entre as mais caras no segmento sabão em pó.

Um dos objetivos do teste realizado na residência do pesquisado era perceber se a sensibilização pré-teste, com o argumento de sustentabilidade provocaria a percepção de valores intangíveis, a ponto de levar o usuário a se pré-dispor mais favoravelmente em relação à marca teste. Assim, a qualidade do produto Marca livre de fosfato seria testada quanto a argumentos tangíveis. As perguntas foram realizadas com o objetivo de comparar o produto testado com o utilizado pelo consumidor. Quanto a capacidade espumante a pergunta era: "o produto Marca livre de fosfato possui a mesma capacidade espumante do que a marca que compro na atualidade". Esse mesmo padrão de pergunta, além da capacidade espumante, foi feio para os seguintes atributos: facilidade de enxágue; aroma; manter cor, aspecto e textura 
dos tecidos; qualidade em limpeza (tira manchas) e; rendimento. Os resultados são apresentados na Tabela 2.

Tabela 2 - Quanto ao atributo selecionado, a Marca livre de fosfato possui a mesma capacidade da marca atualmente utilizada? (em \%)

\begin{tabular}{|l|c|c|c|c|c|}
\hline Atributo selecionado & $\begin{array}{l}\text { Concordo } \\
\text { Totalmente }\end{array}$ & Concordo & Não Concordo & Discordo & $\begin{array}{l}\text { Discordo } \\
\text { Totalmente }\end{array}$ \\
\hline Capacidade espumante & 22 & 42 & 34 & 00 & 02 \\
\hline Facilidade de enxágue & 44 & 49 & 07 & 00 & 00 \\
\hline Aroma & 41 & 49 & 10 & 00 & 00 \\
\hline $\begin{array}{l}\text { Mantém a cor, aspecto e } \\
\text { textura dos tecidos }\end{array}$ & 54 & 44 & 02 & 00 & 00 \\
\hline Qualidade da limpeza & 32 & 59 & 07 & 02 & 00 \\
\hline Rendimento & 27 & 53 & 10 & 10 & 00 \\
\hline Média dos atributos & 36,66 & 49,33 & 11,66 & 2,02 & 0,33 \\
\hline
\end{tabular}

Fonte: Pesquisa experimento

Observa-se que quatro, entre seis atributos pesquisados, apresentaram resposta superior a $90 \%$ de concordância, ou seja, os consumidores concordam que o produto testado tem os mesmos atributos que o consumido habitualmente. Apenas capacidade espumante (64\%) e rendimento (69\%) possuem concordância menor de $90 \%$. Ou seja, é clara percepção do consumidor, após o experimento, que há um elevado potencial de substituição entre os produtos atualmente utilizados e o produto objeto do teste.

O próximo passo do trabalho foi pesquisar se, percebido o elevado grau de substituição entre os produtos, os consumidores prefeririam aquele que traz um maior apelo à sustentabilidade. Para tanto, foi elaborada a pergunta: "eu estaria disposto a trocar a marca de sabão em pó que compro habitualmente por esta ora testada, se soubesse tratar-se de um produto ambientalmente mais correto". A resposta a esta questão é apresentada no Gráfico 1, com o título resumido de "disposição do consumidor a trocar de marca".

Quando a pergunta não faz referência ao preço do produto é nítida a disposição do consumidor em alterar seus hábitos de consumo. Oitenta e nove por cento (89\%) dos consumidores se mostraram dispostos a substituir a marca que consumiam pela marca com características de sustentabilidade ambiental. Esta informação pode ser incorporada a função de produção das empresas. Como já embasado, Oliveira (2004) acredita que a realização de estudos constantes dos ambientes internos e externos é uma oportunidade para as empresas localizarem brechas e nichos mercadológicos.

Ao incorporar na pergunta o preço há uma pequena alteração nas preferências do consumidor, embora ainda haja uma forte disposição de substituição dos produtos. A pergunta do questionário foi: "caso este sabão tenha o mesmo preço que a marca que uso hoje, sinto-me com a seguinte sensação sobre passar a usá-lo". 
Gráfico1 - Disposição do consumidor a trocar de marca

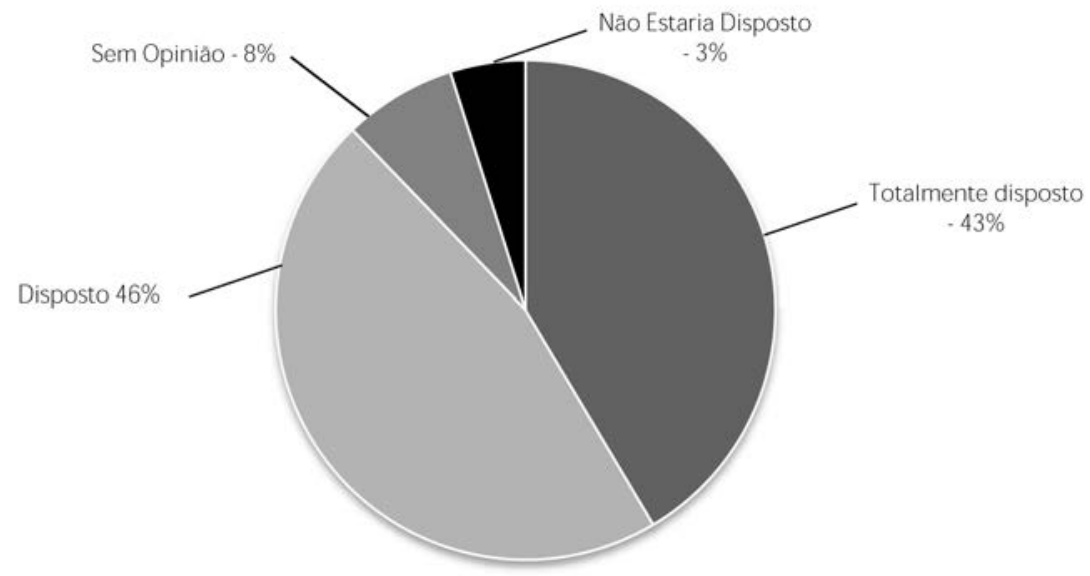

Fonte: Pesquisa experimento.

Gráfico 2 - Disposição do consumidor a trocar de marca quando os produtos possuem o mesmo preço

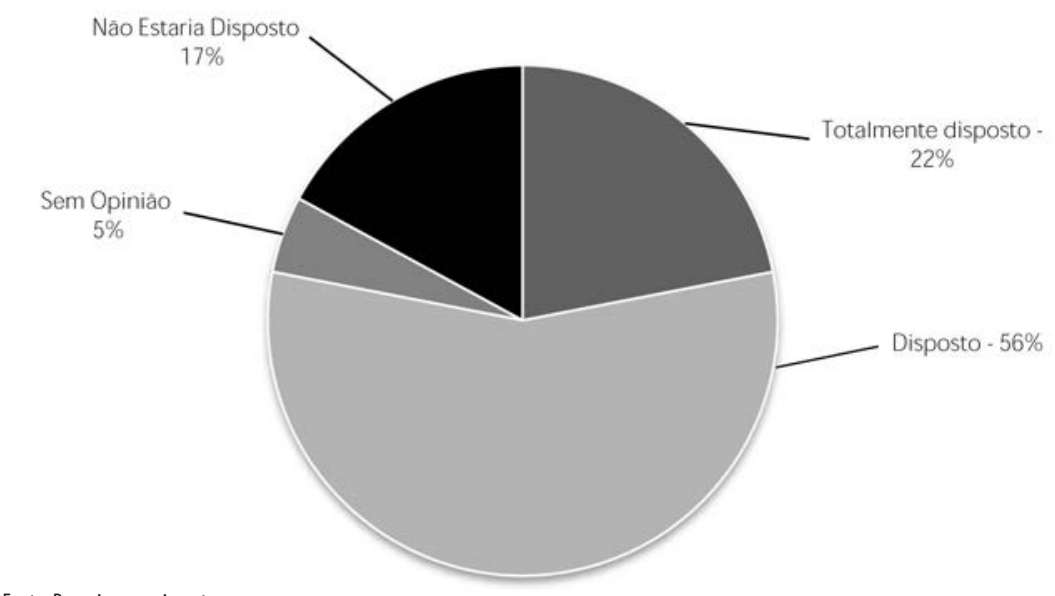

Fonte: Pesquisa experimento.

O Gráfico 2 mostra que 78\% dos entrevistados, caso o produto da pesquisa Marca Livre de Fosfato - tenha o mesmo preço do produto que usam hoje, estariam dispostos a trocar de marca. Na tentativa de aprofundar essa percepção de preferência do consumidor pela marca com apelo ambiental, foi elaborada outra pergunta, mais específica, que estipula um preço médio para o sabão em pó. A pergunta foi: "ao preço de $\mathrm{R} \$ 5,00$ que marca você prefere?". A maioria dos consumidores (55\%) relatou preferir 
a Marca livre de fosfato, 36\% escolheram a Marca Top e apenas 9\% escolheram uma outra marca. Aparentemente parece haver uma inconsistência na escolha do produto com ênfase ambiental. Quando não é sugerido o preço 78\% dos consumidores optaram pela Marca livre de fosfato. Após a sugestão do preço de R\$ 5,00, a proporção de propensos à troca continua alta, mas cai para 55\%. Possivelmente a diferença se dá pelo fato de, quando do mesmo preço, $23 \%$ dos entrevistados preferir migrar para a top, e não para a ambiental.

A última pergunta da pesquisa é uma tentativa de investigar a disponibilidade a pagar pelo produto. A pergunta foi feita com relação aos produtos Marca livre de fosfato e Marca Top. Foram sugeridos ao consumidor nove preços distintos, a saber: $\mathrm{R} \$ 4,00$; $\mathrm{R} \$$ 5,25; $R \$ 5,50 ; \mathrm{R} \$ 5,75 ; \mathrm{R} \$ 6,00 ; \mathrm{R} \$ 6,25 ; \mathrm{R} \$ 6,50 ; \mathrm{R} \$ 6,75 ; \mathrm{R} \$ \mathrm{7,00}$. Os resultados são apresentados nos Gráficos 3 e 4. Os Gráficos apresentam o preço que o consumidor está disposto a pagar e o percentual de consumidores que escolheram aquele nível de preços.

A análise dos Gráficos 3 e 4 revela um comportamento bastante similar entre os dois produtos testados. A época da pesquisa os produtos de Marca livre de fosfato e Marca top possuíam preços similares, variando em torno de $\mathrm{R} \$ 5,50$ à $\mathrm{R} \$ 5,67$. Obviamente, para os dois produtos, os consumidores optaram por preços mais reduzidos, sendo que o preço modal escolhido foi de $\mathrm{R} \$ 5,20$. Os valores da disponibilidade a pagar ratificam a percepção de que os consumidores estão dispostos a substituir os produtos atualmente utilizados, e até o produto top of mind por produtos ambientalmente corretos.

Para níveis de preços mais elevados que os praticados pelo mercado os resultados não foram conclusivos. Quando os preços são de R\$ 6,00 o percentual de preferencias

Gráfico 3 - Predisponho-me a comprar a Marca livre de fosfato ao preço de

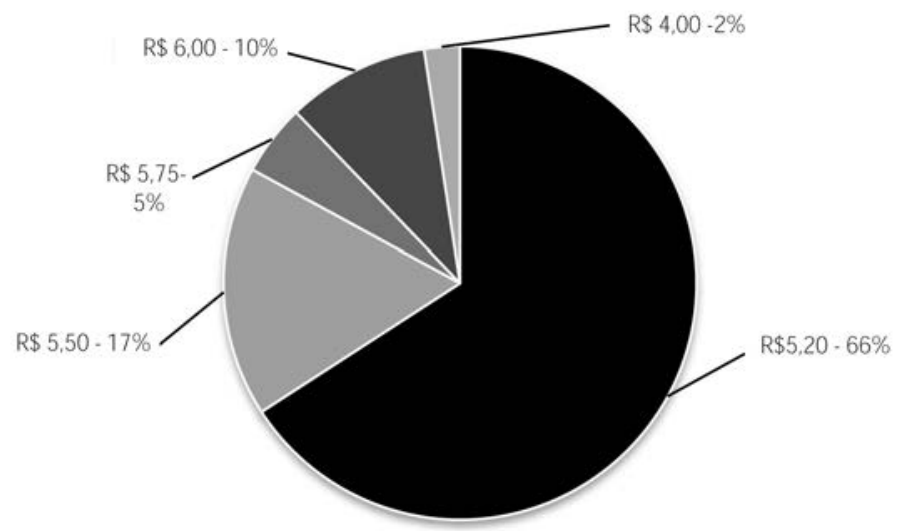

Fonte: Pesquisa experimento. 
é bastante parecido: $10 \%$ para o a Marca livre de fosfato e $9 \%$ para a Marca top. Para preços mais elevados aparecem, em percentual reduzido (4\%), apenas consumidores para o produto Top. Somente um consumidor escolheu um preço ( $R \$ 4,00)$ fora da realidade praticada pelo mercado, mostrando a seriedade com que os respondentes encaram a pesquisa.

Gráfico 4 - Predisponho-me a comprar a Marca top ao preço de

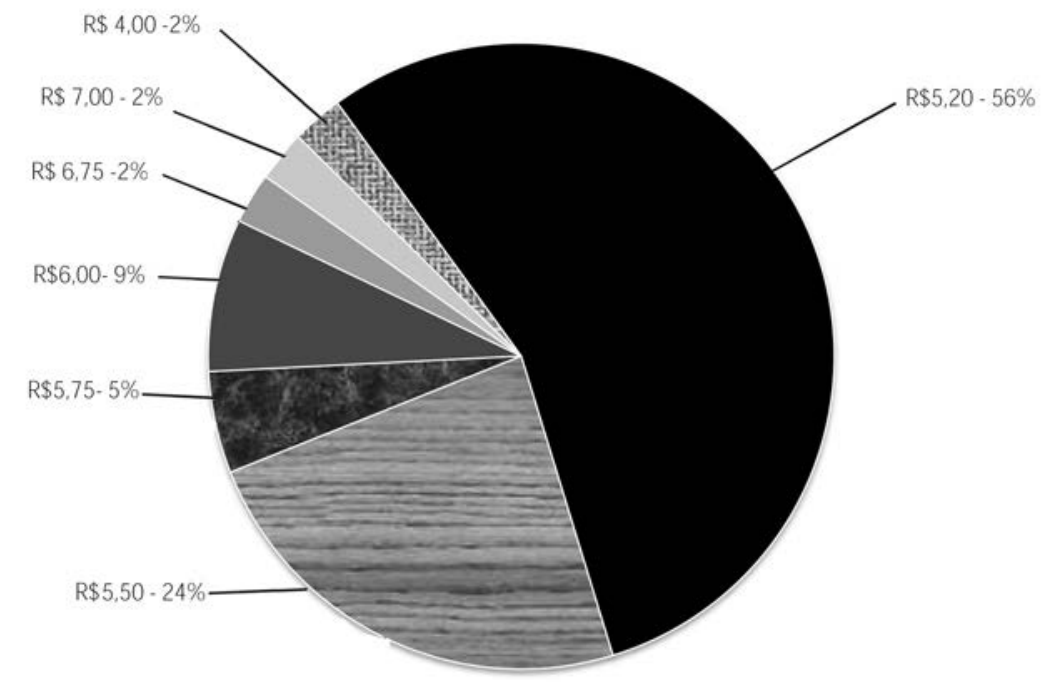

Fonte: Pesquisa experimento.

\section{Considerações Finais}

A percepção da necessidade de ações efetivas em prol da sustentabilidade ambiental tem provocado pesquisadores, autores e gestores à melhor compreensão sobre o real interesse do consumidor por produtos e marcas que se posicionam com o argumento de melhor performance ambiental. A crise dos recursos naturais renováveis é importante fator a ser analisado no macroambiente natural para as tomadas de decisões estratégicas nas organizações.

Neste cenário, o estudo busca o entendimento teórico sobre estratégias empresariais e sobre formação de valor de marcas e produtos, seguido de busca de campo sobre o interesse dos consumidores pela sustentabilidade. $\mathrm{O}$ estudo sugere que o consumidor, a partir da informação e crença sobre a real eficiência ambiental da marca, está disposto a dar preferência aos produtos sustentáveis, desde que os demais atributos de qualidade sejam mantidos. 
Por meio de um experimento, observou-se que o produto utilizado como teste, a Marca livre de fosfato mantém os atributos de qualidade do produto que o consumidor está acostumado a utilizar. Entre seis atributos pesquisados, quatro apresentaram resposta superior a $90 \%$ de concordância de que o produto testado tem os mesmos atributos que o consumido habitualmente. Dois atributos obtiveram respostas de $64 \%$ e $69 \%$ de concordância, o que indica, também, um ótimo desempenho do produto testado, comprovando que ele possui qualidade similar ao produto empregado pelo consumidor, tendo portando um elevado potencial de substituição com o produto atualmente utilizado.

A indicação de que os consumidores estão dispostos a trocar de marca também é um resultado bastante claro na pesquisa. Considerando que os produtos possuem o mesmo preço, 78\% dos consumidores declaram estar dispostos a trocar de marca, indicando a existência de um consumidor sensibilizado para as questões ambientais, que daria preferência a produtos que causam menor impacto sobre a sustentabilidade do Planeta.

Quando os consumidores foram submetidos à questão da disponibilidade a pagar, respondendo à pergunta central do artigo: os consumidores estão dispostos a pagar pela sustentabilidade ambiental? Observa-se que o consumidor se mostra propenso a pagar pelo produto com caraterísticas de sustentabilidade o mesmo preço do produto mais vendido no mercado, revelando que ele incorporou a questão da sustentabilidade em suas escalas de preferências. Os valores da disponibilidade a pagar ratificam a percepção de que os consumidores estão dispostos a substituir os produtos atualmente utilizados, e, até o produto top of mind por produtos ambientalmente corretos.

Os resultados do estudo não são conclusivos quando o produto com caraterísticas sustentáveis possui um preço mais elevado que o produto atualmente consumido. Outra limitação do estudo é que ele foi realizado apenas com consumidores pertencentes às classes $A$ e $B$, fato que pode causar algum viés, tendo em vista a menor restrição orçamentária dessas classes sociais. Ou seja, não sabemos como as classes de menor renda, quando expostas ao experimento se comportariam. Embora com essas limitações, os resultados da pesquisa apontam que o atributo de sustentabilidade, agregado ao produto, representa um desejo dos consumidores. A disposição a pagar por estes atributos está evidenciada no discurso de quase todos os consumidores pesquisados. A presença de atributos de eco eficiência faz com que o consumidor substitua a marca habitual de consumo pelo produto eco eficiente, desde que ele possua características de qualidade parecidas e preços similares.

\section{Nota}

' Desenvolvida por Rensis Likert, a escala Likert permite a variação de respostas objetivas a cinco níveis em cada questão. Geralmente varia entre o muito positivo e o muito negativo. 


\section{Referências bibliográficas}

BERNSTEIN, Peter L. Desafio aos deuses: a fascinante história do risco. Rio de Janeiro: Campus, 1997.

CAPRA, Fritjof. As conexões ocultas. Ciência para uma vida sustentável. São Paulo: Editora Cultrux, 2002. 296p.

ELKINGTON, John. Canibais com garfo e faca. São Paulo: Editora Makron Books, 2000.

ETHOS; AKATU. Pesquisa Percepção do Consumidor Brasileiro. São Paulo: Market Analysis, Instituto Ethos e Instituto Akatu, 2007. Disponível em <http://www.ethos.org.br/_Uniethos/ Documents/Sumario_RSE_2006_2007_Ethos_Akatu.pdf>. Acesso em 03 mar 2010.

HAWKEN, P.; LOVINS, A.; LOVINS, L.H.: Capitalismo Natural. 13 ed. São Paulo: Pensamento/ Cultrix, 1999.357p.

KOTLER, P.; KARTAJAYA, H.; SETIANWAN; I. Marketing 3.0: As forças que estão definindo o novo marketing centrado no ser humano. Rio de Janeiro: Elsevier, 2010, 215p.

KOTLER, Philip. Administração de marketing. 10 ed. São Paulo: Prentice Hall, 2000. 763p.

KOTLER, Philip e ROBERTO, Eduardo L. Marketing Social: estratégias para alterar o comportamento público. Rio de Janeiro: Campus, 1992.

MANAGEMENT \& EXCELLENCE. Return on Sustainability: índice de medição de retorno financeiro. IBMEC); ROS ${ }^{\oplus}$ 2 2009. Disponível em <http://www.management-rating.com/index. php?lng=pt\&cmd=210>. Acesso em 26 nov 2010.

MANAGEMENT \& EXCELLENCE. As empresas mais transparentes do IBOVESPA - 2010. São Paulo, agosto de 2010.31p.

OLIVEIRA, Djalma de P.R. Planejamento Estratégico - conceitos, metodologia e práticas. São Paulo: Editora Atlas, 2004.

PORTER, Michael E. Vantagem competitiva: criando e sustentando um desempenho superior. Rio de Janeiro: Campus, 1990

REVISTA CONJUNTURA ECONÔMICA. Sustentabilidade: Negócio de empresas, Vol. 63. N.10. Brasília: Instituto Brasileiro de Economia, Fundação Getúlio Vargas, 2009, p.36.

SACHS, Ignacy. Estratégias de transição para o século XXI: desenvolvimento e meio ambiente. São Paulo: Studio Nobel; Fundap, 1993.

UNIETHOS. Responsabilidade Social das Empresas - Percepção do Consumidor Brasileiro 2006 e 2007. Disponível em http://www.uniethos.org.br/_Uniethos/Documents/consumidor_2002.pdf. Acesso em 03 jul 2010.

WWF - World Wildlife Fund. Relatório bi-anual Planeta Vivo. Disponível em <http://www.wwf. org.br/informacoes/?uNewsID=26162>. Acesso em 28 nov 2010.

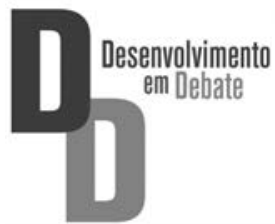

